\title{
Real magic: future studies of magic should be grounded in neuroscience
}

\author{
Stephen L. Macknik and Susana Martinez-Conde
}

We recently proposed, in collaboration with five professional magicians, that neuroscientists and magicians should join forces in the study of human perception and cognition (Attention and awareness in stage magic: turning tricks into research. Nature Rev. Neurosci. 9, 871-879 (2008))1 ${ }^{1}$. Our two-pronged approach was that, first, magic techniques could be used as powerful tools in cognitive neuroscience research, and that, second, the perception of magic tricks will be best understood from a neurobiological perspective.

While commending our Perspective, Lamont and Henderson (Nature Rev. Neurosci. 29 Jan 2009 (doi:10.1038/ nrn2473-c1) $)^{2}$ point out that scientific interest in magic is not new, and that previous attempts to establish a theory of magic have failed. They also mention that Lamont and Wiseman's classification of conjuring effects $^{3}$ - adopted in our Perspective - did not merely list the main categories, but also indicated the methods behind the tricks. Finally, they refer to Simons and Chabris' classic study of inattentional blindness ${ }^{4}$, and propose that observers that look directly at the gorilla will not fail to notice it. We address these points below.

To the best of our knowledge, our recent Perspective represents the first effort to systematize the study of magic from a neuroscientific, rather than a psychological, perspective. One should also note that a significant fraction of the psychological literature cited by Lamont and Henderson is comprised of editorials and opinion pieces (such as REFS 5,6) rather than experimental work. Further, the only 'physiological' study mentioned did not address the physiological bases of the perception of magic: it simply sought to find out whether magicians had superior perceptual and motor skills to those of control subjects (not surprisingly, they did not $)^{7}$. Lamont and Henderson agree with our evaluation of Kuhn and
Tatler's paper ${ }^{8}$ as "...the first study to have correlated the perception of magic with any physiological measurement" (REF. 1). Thus, interest in the psychology of magic has waxed and waned, but interest in the neuroscience of magic is novel (see also REFS 9,10). Indeed, the neuroscientific study of magic has already proved more productive (with just a handful of studies over the past few years) than previous attempts at psychological magic theory. Lamont and Henderson kindly note that our Perspective is more focused than previous efforts; we further believe that it brings forth a significant shift in focus.

Lamont and Wiseman deserve high praise for their pioneering efforts, and their book on magic theory is extensively cited throughout our Perspective. We are aware that their original classification included a description of the mechanics by which magic tricks are accomplished. However, to fully understand why a magic trick works, one must go beyond the physical mechanics of the trick, and even beyond psychological explanations. That is, to understand how magic tricks are perceived, one must identify the underlying neural correlates. Such neuroscientific accounts of magic may provide fresh new insights into the brain mechanisms of perception and cognition.

Is it possible to miss changes in objects that one directly looks at? Contrary to Lamont and Henderson's evaluation, the literature indicates that observers often look but do not see. As our Perspective describes, Memmert ${ }^{11}$ found that observers who missed the gorilla in the Simons and Chabris ${ }^{4}$ video spent as much time $(\sim 1$ second) looking at it as those who detected it. O'Regan et al. ${ }^{12}$ similarly found, in a change blindness study, that even when observers directly fixated the change locations (within $1^{\circ}$ ) they still failed to see the changes $40 \%$ of the time. Kuhn and Tatler ${ }^{8}$ recently investigated the role of gaze position in the detection of magic tricks, and found that detection rates were not significantly influenced by how far the target was from the centre of vision at the time of its disappearance. Thus they concluded that the magician primarily manipulates the spectators' attention rather than their gaze. A wonderful video featuring an experiment by Henderson (who co-authored the reply to our Perspective) and Tim J. Smith further supports this idea (see the Continuity Boy blog for further details). Henderson and Smith tracked the eye movements of nine observers viewing Richard Wiseman's Colour Changing Card Trick. In the video narrator's words, the only subject that noticed the change "...was looking in exactly the same place as all of the others." Thus, although Lamont and Henderson assert that when observers "....are looking at a changing object, they notice the change" (REF. 2), Henderson's own research shows otherwise.

Future research on the neural bases of magic should follow in the footsteps of studies such as these. We are confident that a clearer picture will emerge as the neuroscience of magic gains footage, aided by brain imaging and other neural activity recording techniques.

Stephen. L. Macknik and Susana Martinez-Conde are at the Barrow Neurological Institute, 350 West Thomas Road, Phoenix, Arizona 85013, USA.

Correspondence to S.M.C. e-mail:smart@neuralcorrelate.com

1. Macknik, S. L. et al. Attention and awareness in stage magic: turning tricks into research. Nature Rev. Neurosci. 9, 871-879 (2008).

2. Lamont, P. \& Henderson, J. M. More attention and greater awareness in the scientific study of magic. Nature Rev. Neurosci. 29 Jan 2009 (doi: 10.1038/ nrn2473-c1).

3. Lamont, P. \& Wiseman, R. Magic in Theory (Hermetic Seattle, Washington, 1999).

4. Simons, D. J. \& Chabris, C. F. Gorillas in our midst: sustained inattentional blindness for dynamic events. Perception 28, 1059-1074 (1999)

5. Gregory, R. L. Conjuring. Perception 11, 631-633 (1982).

6. Trinkaus, N. Preconditioning an audience for mental magic. Percept. Mot. Skills 51, 262 (1980).

7. Jastrow, J. Psychological notes upon sleight-of-hand experts. Science 3, 685-689 (1896).

8. Kuhn, G. \& Tatler, B. W. Magic and fixation: now you don't see it, now you do. Perception 34, 1155-1161 (2005).

9. Martinez-Conde, S. \& Macknik, S. L. Magic and the brain. Sci. Am. 299, 72-79 (2008)

10. Martinez-Conde, S. $\&$ Macknik, S. L. Mind tricks. Nature 448, 414 (2007).

11. Memmert, D. The effects of eye movements, age, and expertise on inattentional blindness. Conscious. Cogn. $15,620-627$ (2006)

12. O'Regan, J. K., Deubel, H., Clark, J. J. \& Rensink, R. A. Picture changes during blinks: looking without seeing and seeing without looking. Vis. Cogn. 7, 191-211 (2000). 